\title{
Short communication: Pre- and postmilking anatomical characteristics of teats and their associations with risk of clinical mastitis in dairy cows
}

\author{
J. F. Guarín ${ }^{*} \dagger^{1}$ and P. L. Ruegg* \\ *Department of Dairy Science, University of Wisconsin, Madison 53706 \\ †Grupo de Investigación Biogénesis, Facultad de Ciencias Agrarias, Universidad de Antioquia, Medellín, Colombia, 050031
}

\begin{abstract}
The primary objective of this study was to describe and compare anatomical characteristics of teats before and after machine milking adjusted for parity and teat location (front versus rear). The second objective was to determine if selected milking and anatomical characteristics of teats were associated with occurrence of clinical mastitis. To address objective 1, a crosssectional study was done to describe and compare teat dimensions before and after milking $(\mathrm{n}=1,751$ teats from 445 cows). To fulfill objective 2, a case-control study was performed. Quarters having their first case of clinical mastitis in the current lactation from 2 mo before to 2 mo after the day the teats were measured were selected as cases $(n=47)$, provided no other quarters from that cow were affected by clinical mastitis at that time. Three controls $(\mathrm{n}=141)$ were matched with each case; these were selected from quarters that did not experience any case of clinical mastitis during their current lactation. A conditional logistic regression model was used to determine associations between teat dimensions and occurrence of clinical mastitis. Primiparous and multiparous Holstein cows were enrolled in both studies. As compared with premilking dimensions, postmilking teats were longer and narrower at the barrel and the apex. Significant interactions between teat position and parity were identified for premilking teat length and diameter of the teat barrel. Premilking, teats were longer and wider with increasing parity. Front teats were longer and wider than rear teats premilking. Also during premilking, differences between the front and rear teat were less at increasing parity. Teat apex diameter was greater for premilking teats of cows in parity $\geq 3$ and the apexes of front teats were wider than those of rear teats. Teats enrolled in the case-control study had twice as many clinical mastitis
\end{abstract}

Received July 9, 2015.

Accepted May 24, 2016.

${ }^{1}$ Corresponding author: guarinmontoy@wisc.edu cases in front quarters compared with rear quarters. Premilking diameter of the teat apex was positively associated with risk of clinical mastitis (odds ratio $=$ 1.20 per $1-\mathrm{mm}$ increase in the diameter of the apex of the teat, $95 \%$ confidence interval $=1.05-1.37$ ). Milking machine-related changes in teat dimensions had no association with occurrence of clinical mastitis.

Key words: dairy, clinical mastitis, milking machine, teat

\section{Short Communication}

Mastitis is defined as inflammation of the mammary gland, which in the vast majority of cases is caused by IMI (Hogan et al., 1999). Preservation of the teat canal and of the integrity of adjacent tissues is critical to resist infection and prevent mastitis (Seykora and McDaniel, 1985; Zucali et al., 2008). Milking machines can contribute to increased risk of mastitis by influencing health of the teat canal and teat skin (Mein, 2012). Anatomic characteristics of teats can be divided into 3 segments: (1) teat base, which connects the teat to the udder; (2) teat barrel, middle part between the base and the apex, and (3) teat apex, the most distal part of the teat and includes the teat canal (Figure 1A). The dimensions of the teat and milking-induced changes in teat dimensions may be associated with risk of IMI. According to Zwertvaegher et al. (2013), milk from quarters with wider teat barrels (postmilking) had greater quarter level SCC compared with milk from quarters with thinner teat barrels. The primary objective of the current study was to describe and compare anatomical characteristics of teats before and after machine milking adjusted for parity and teat location (front vs. rear). The second objective was to determine if milking and anatomical characteristics of teats were associated with occurrence of clinical mastitis. The first objective was addressed using a cross-sectional study, whereas the second objective was addressed with a case-control study.

The study population consisted of all 445 lactating Holstein cows of the University of Wisconsin Dairy 
Cattle Research Center, and both multiparous ( $\mathrm{n}=$ $273)$ and primiparous $(\mathrm{n}=172)$ cows were eligible for enrollment. All cows were milked in a double 16 parallel milking parlor. Premilking cow preparation consisted of teat disinfection using $0.5 \%$ iodine, removal and observation of foremilk, drying of the teats using cloth towels, followed by unit attachment. Automatic takeoffs (cup removers) were set at a milk flow threshold of $0.6 \mathrm{~kg} / \mathrm{min}$. Following unit removal, teats were dipped in $1 \%$ iodine. The milking machine was set at a pulsation rate of 60 pulsations per min, and milking system vacuum level of $44.5 \mathrm{kPa}$ with a $60 \%$ pulsation ratio. Round teat cup liners (WestfaliaSurge Classic Pro GQ silicone liners head 51; GEA Farm Technologies, 2010, Bönen, Germany) were used. Liners had a mouthpiece opening diameter of $23 \mathrm{~mm}$, mid-barrel diameter (at $75 \mathrm{~mm}$ down) of $20 \mathrm{~mm}$, mouthpiece chamber depth to upper collapse point of $40 \mathrm{~mm}$, lower collapse point (below mouthpiece opening) of $118 \mathrm{~mm}$, and a wall thickness of $2.5 \mathrm{~mm}$.
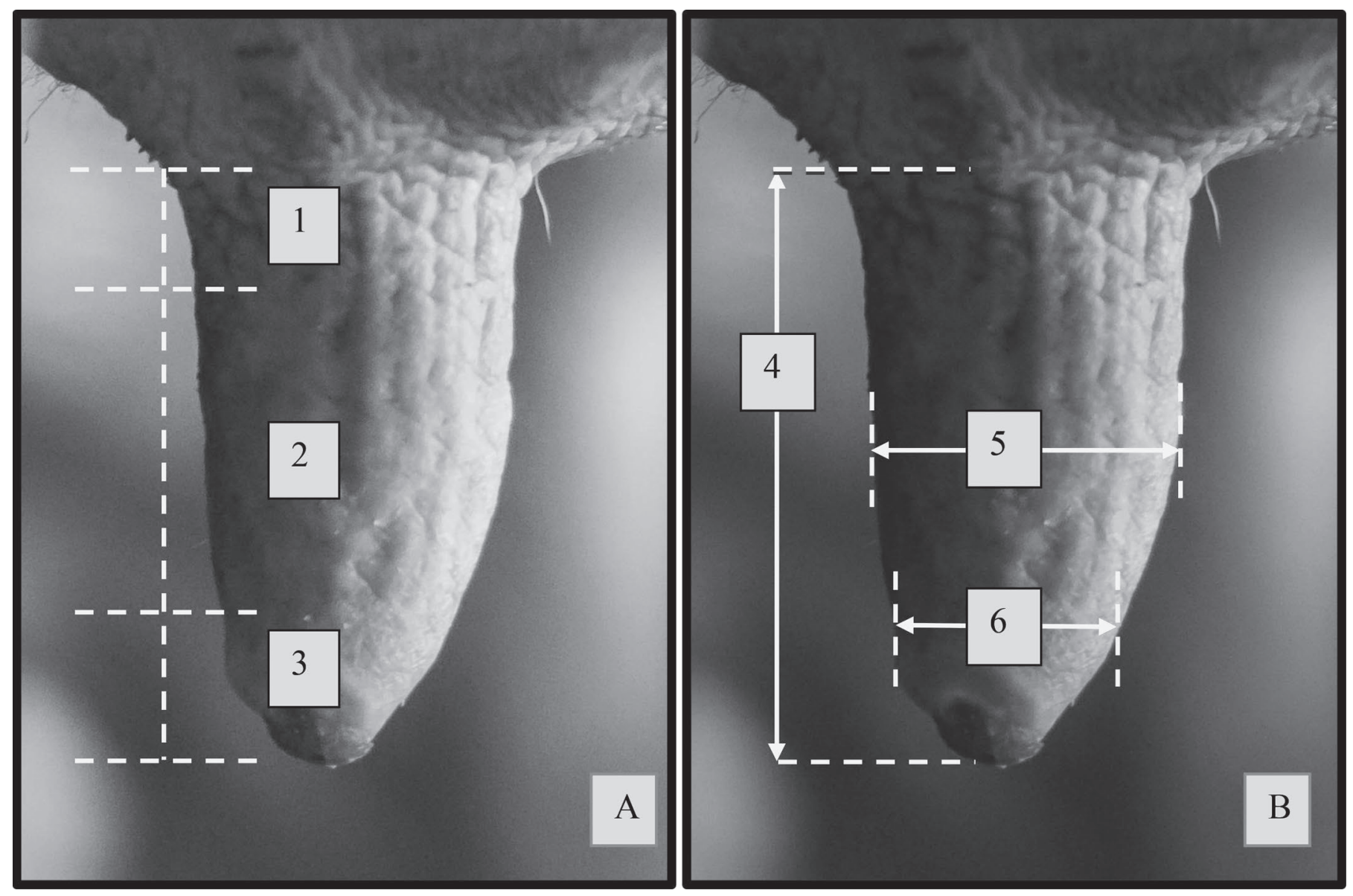

Figure 1. Anatomical portions of the teat and measured segments. (A) Anatomical division of the teats: (1) teat base, (2) teat barrel, and (3) teat apex. (B) Teat segment measured before unit attachment and immediately after automatic unit detachment: (4) teat length, (5) teat barrel diameter, and (6) teat apex diameter. 
lated as absolute change divided by PRE measurements and expressed as a percentage. Congestion at the teat barrel was defined as occurring when POST teat barrel measurements were greater than PRE teat barrel measurements. Individual cow data were obtained from herd management software (DairyComp 305, Valley Agricultural Software, Tulare, CA). Information included parity, DIM on the day when teats were measured, and projected $305 \mathrm{~d}$ milk yield. The parlor management software (DairyPlan C21 version 5.2; WestfaliaSurge Inc.) was set up to record average milk flow at 30 to $60 \mathrm{~s}$ after unit attachment (milk flow rate 60), 60 to 90 s after unit attachment (milk flow rate 90), 90 to 120 s after unit attachment (milk flow rate 120), 120 to $150 \mathrm{~s}$ after unit attachment (milk flow rate 150), 150 to $180 \mathrm{~s}$ after unit attachment (milk flow rate 180), average milk flow rate (from initiation of milk flow to cluster removal), and maximum milk flow rate (defined as the peak flow rate). All milk flow rate variables were expressed in kilograms per minute. The study was approved by the Animal Care and Use Committee at the University of Wisconsin-Madison (protocol A-01-553).

For the case-control study, the experimental unit was the individual quarter. The risk period was defined as 2 mo before and 2 mo after the observation of teat characteristics. Teat were measured between December 26, 2013, and January 24, 2014, during 6 farm visits. Thus, cases were defined as the first single quarter case of clinical mastitis occurring in a cow between November 1, 2013, and March 1, 2014 (risk period). All eligible quarters diagnosed with clinical mastitis during this period were enrolled as cases. Quarters from cows with previous cases of clinical mastitis in the current lactation or with multiple quarters affected simultaneously at the time of occurrence of the cow's first case for the lactation were not eligible to serve as cases. Clinical mastitis was defined as the production of abnormal milk with or without secondary symptoms (Erskine et al., 2003) and was detected by trained milking technicians during premilking preparations. Controls were defined as quarters of cows that did not have any clinical mastitis cases during their current lactation. Each cow contributed only one control quarter that served as a control for a single case. Three controls were randomly selected for each case using a random integer generator (https://www.random.org/integers/), matched by parity (first, second, or third or greater), DIM on the day when teats were measured $(0-30,31-60,61-120$, 121-180, 181-240, or $>240 \mathrm{~d}$ ), and by location of the quarter (front or rear).

All analyses were performed using SAS version 9.3 (SAS Institute Inc., Cary, NC). Individual teats were the experimental unit for the cross-sectional study and descriptive analyses were performed to examine distributions of all explanatory variables. The PROC TTEST was used to perform paired-samples $t$-tests between PRE and POST measurements for each of the measured segments of the teats. For each measured teat segment (length, barrel diameter, and apex diameter) linear regression models were fitted using PROC MIXED to test the null hypothesis that there was no difference in dimensions among parity groups, position of the quarter, or the interaction between these 2 terms. When the overall $P$-value for the interaction terms was not significant, those terms were removed from the model and just the main effects fitted. Then, only main effects were reported (LSM and associated $\mathrm{SE}$ ) for each teat position category and for each parity. Otherwise, if the interaction terms were retained in the model, separate least squares means, and associated standard errors were reported for each of the 6 teat position by parity combinations. Linear regression models were performed for each measurement (PRE or POST) and for the relative changes on teat dimensions. In each of these linear regression models, cow was used as a random effect to account for the clustering of teat within cow.

The individual quarter was the experimental unit for the case-control study. To avoid multicollinearity, highly correlated explanatory variables were determined using correlation coefficients calculated using PROC CORR, and those variables detected as highly correlated were not allowed to enter in the multivariable modeling process together. High correlation between variables was considered when $\mathrm{r}>0.66$. Postmilking measurements were highly correlated with their corresponding premilking measurements and were thus not used in the final model. Instead, the potential influence of the milking machine on teat characteristics was assessed using the relative changes in teat dimensions, which related both POST and PRE measurements. Conditional logistic regression using PROC LOGISTIC was used to determine the effect of putative risk factors on clinical mastitis (response variable). Conditional logistic regressions were conditional on group, where each group was a case and its 3 matched controls. To fulfill assumptions of linearity of explanatory variables and log odds in the logistic regression, the relationship between both factors was evaluated. Each continuous response variable was converted into an ordinal categorical variable and the number of events in each category was calculated. To assess linearity, the logit of the number of cases to number of controls were calculated for each exposure category and graphed versus the ordinal values for each of the explanatory variables. With the exception of the relative change at the teat apex, all variables were linear during this evaluation. Relative change at the teat apex was categorized into 3 levels to be offered to the 
conditional logistic model. The 3 levels defined for this variable were negative change, no change, and positive change, reflecting quartiles 1,2 and 3 , and 4 of the distribution for this variable, respectively. Explanatory variables unconditionally associated with occurrence of clinical mastitis (at $P \leq 0.25$ ) were first introduced into a full model and then removed or re-entered into the model using a backward stepwise selection method. Only variables at $P \leq 0.05$ were retained in the model.

Enrolled cows had a mean of 2.6 (range 1-6) lactations and produced on average 14,352 $\pm 2,279 \mathrm{~kg}$ of milk per lactation. Descriptive characteristics of enrolled teats and results of models for pre- and postmilking and milking machine-induced relative changes are shown in Table 1. Measurements were obtained from 1,751 teats from 445 cows. Twenty-nine teats of 29 cows were not functional and were not measured. As compared with premilking dimensions, postmilking teats were longer and narrower at the barrel and the apex $(P<0.001)$. For all outcomes, statistical significance for teat position, parity, and the interaction of these 2 factors are reported (Table 1). A significant interaction was found between teat position and parity for premilking length and barrel diameter $(P<0.001$; Table 1$)$. Front teats were longer than rear teats, although the difference for front over rear was less with greater parity (Table 1). Front teat barrels were wider than rear teat barrels, although the difference for front over rear increased with greater parity (Table 1). No interaction between position and parity was identified for premilking teat apex diameter $(P=0.728)$. For premilking diameter of the teat apex, the main effects of parity $(P<0.001)$ and position were significant $(P<0.001$; Table 1$)$. Teat apex diameter was greater for cows in parity $\geq 3$ and the apex of front teats was wider than rear teats.

A significant interaction between teat position and parity was identified for postmilking teat length $(P=$ $0.039)$ but not for postmilking diameter of the teat barrel $(P=0.062)$ or teat apex $(P=0.936)$. Postmilking, front teats were longer than rear teats, although the increase for front over rear was less with greater parity (Table 1). Front teats of cows in parity $\geq 3$ were longer than teats of other parities or position after milking ( $P$ $<0.05)$. Postmilking, the diameter of the teat barrel of primiparous cows was less than the diameter of barrels of second lactation cows $(P=0.03)$, and of third or greater lactation cows $(P<0.001)$. The width of the barrels and teat apexes was greater for front versus rear teats $(P<0.001$; Table 1$)$, but no difference was seen in postmilking teat apex diameter among parities $(P=$ 0.287; Table 1). Differences in the length of the teats between front and rear teats decreased with increasing parity. For both pre- and postmilking teat dimensions, length of both front and rear teats increased with parity.

For relative changes in teat length, an interaction between teat position and parity was identified $(P<$ 0.022; Table 1). For primiparous cows, greater relative increase in rear teats was observed as compared with front teats $(P<0.05)$, but similar increases were observed for multiparous cows. Interactions between teat position and parity were not identified for the diameters of teat barrels or apexes $(P>0.869)$. Milkinginduced changes in teat barrel and apex diameter were influenced by parity with greater relative decreases in diameter of teat barrels and teat apexes observed as parity increased. Teat apexes of cows in parity $\geq 3$ were different only from primiparous cows $(P<0.026$; Table 1). Quarter position was associated with relative change of teat barrels and greater relative change occurred in front teats as compared with rear teats $(P<$ 0.001; Table 1). Relative change of teat apex diameters was not associated with quarter position $(P=0.126$; Table 1). Of 1,751 teats, $163(9.3 \%)$ teat barrels were congested after milking.

Of measured teats, 47 were defined as cases, and 141 were matched as controls (Table 2). Within cases, twice as many clinical mastitis cases were present in front quarters compared with rear quarters (32 cases vs. 15 cases). The distribution of microbiological results (data not shown; routinely inspected in the University of Wisconsin-Madison Milk Quality Laboratory) for these clinical mastitis cases was gram-negative (34\%), culture negative (26\%), Streptococcus spp. (22\%), contaminated (17\%), and Staphylococcus spp. (4\%).

Putative risk factors that were unconditionally associated with risk of clinical mastitis at $P \leq 0.25$ were PRE length, PRE barrel diameter, PRE apex diameter, and relative change in the teat diameter at the apex (Table 3). No cow level production or milk flow variables were eligible for entry into the multivariable model (Table 3). Likewise, except for the milking machine-induced relative change of the teat apex diameter, no milking-machine induced changes were eligible for entry into the multivariable model (Table 3). After backward elimination, the only factor that remained in the conditional logistic model was premilking teat apex diameter. This factor was significantly associated with developing clinical mastitis $(\beta=0.18, \mathrm{SE}=0.07 ; P=$ 0.009 ). Conditional logistic regression of the occurrence of clinical mastitis on the premilking teat apex diameter produced an odds ratio for each $1 \mathrm{~mm}$ increase in the apex dimension of 1.20 (95\% CI: 1.047-1.37).

In this study, premilking diameter of the teat apex was observed to be a risk factor associated with increased clinical mastitis. The odds ratio of this char- 
SHORT COMMUNICATION: TEAT CHARACTERISTICS

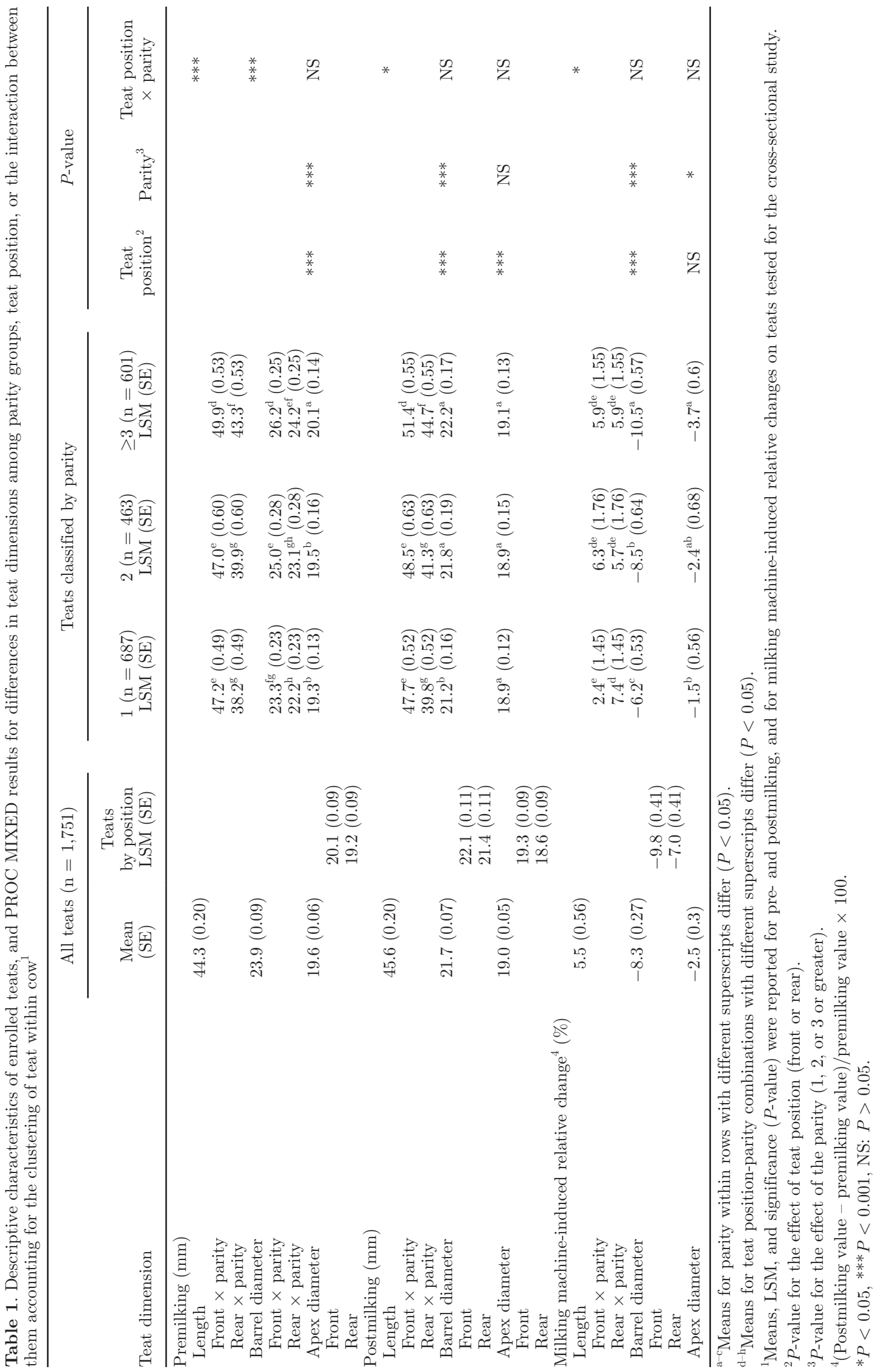


Table 2. Descriptive characteristics of teats of the cases and controls

\begin{tabular}{|c|c|c|c|c|c|c|}
\hline Teat dimension & \multicolumn{3}{|c|}{ Cases $(\mathrm{n}=47)$} & \multicolumn{3}{|c|}{ Controls $(\mathrm{n}=141)$} \\
\hline Teat barrel diameter & 25.7 & 0.8 & $20.0-50.0$ & 24.2 & 0.3 & $14.0-40.0$ \\
\hline Teat apex diameter & 20.6 & 0.4 & $16.0-30.0$ & 19.3 & 0.2 & $14.0-30.0$ \\
\hline \multicolumn{7}{|l|}{ Postmilking (mm) } \\
\hline Teat apex diameter & 19.6 & 0.3 & $14.0-30.0$ & 18.7 & 0.2 & $10.0-24.0$ \\
\hline \multicolumn{7}{|c|}{ Milking machine-induced relative change ${ }^{1}(\%)$} \\
\hline Teat length & 9.5 & 3.3 & $-45.5-50.0$ & 7.8 & 2.2 & $-70.0-90.9$ \\
\hline Teat barrel diameter & -10.6 & 1.5 & $-35.3-10.0$ & -9.2 & 1.0 & $-40.0-20.0$ \\
\hline Teat apex diameter & -4.6 & 1.1 & $-33.3-11.1$ & -2.2 & 1.2 & $-33.3-42.9$ \\
\hline
\end{tabular}

${ }^{1}($ Postmilking value - premilking value $) /$ premilking value $\times 100$.

acteristic was 1.2 , which represents a $20 \%$ increase in the odds of developing clinical mastitis for each $1 \mathrm{~mm}$ increase in the premilking diameter of the apex of the teat. This increased risk for developing mastitis may be due to wider teat canals and larger teat orifices in wider teats. Wider teat canals and sphincter muscles that cannot efficiently close the teat orifice are both associated with wider teat diameters, increased milk flow rates, and greater milk production in dairy cows (Seykora and McDaniel, 1985). Teats that have patent teat canals are more likely to get infections than teats with proper functional teat canals (Seykora and McDaniel, 1985). Norwegian red cows subjectively assessed to have teat diameters that were greater than

Table 3. Unadjusted estimates, SE, odds ratios, and 95\% CI for explanatory variables tested for association with occurrence of clinical mastitis from conditional logistic regression models of data from the case-control study

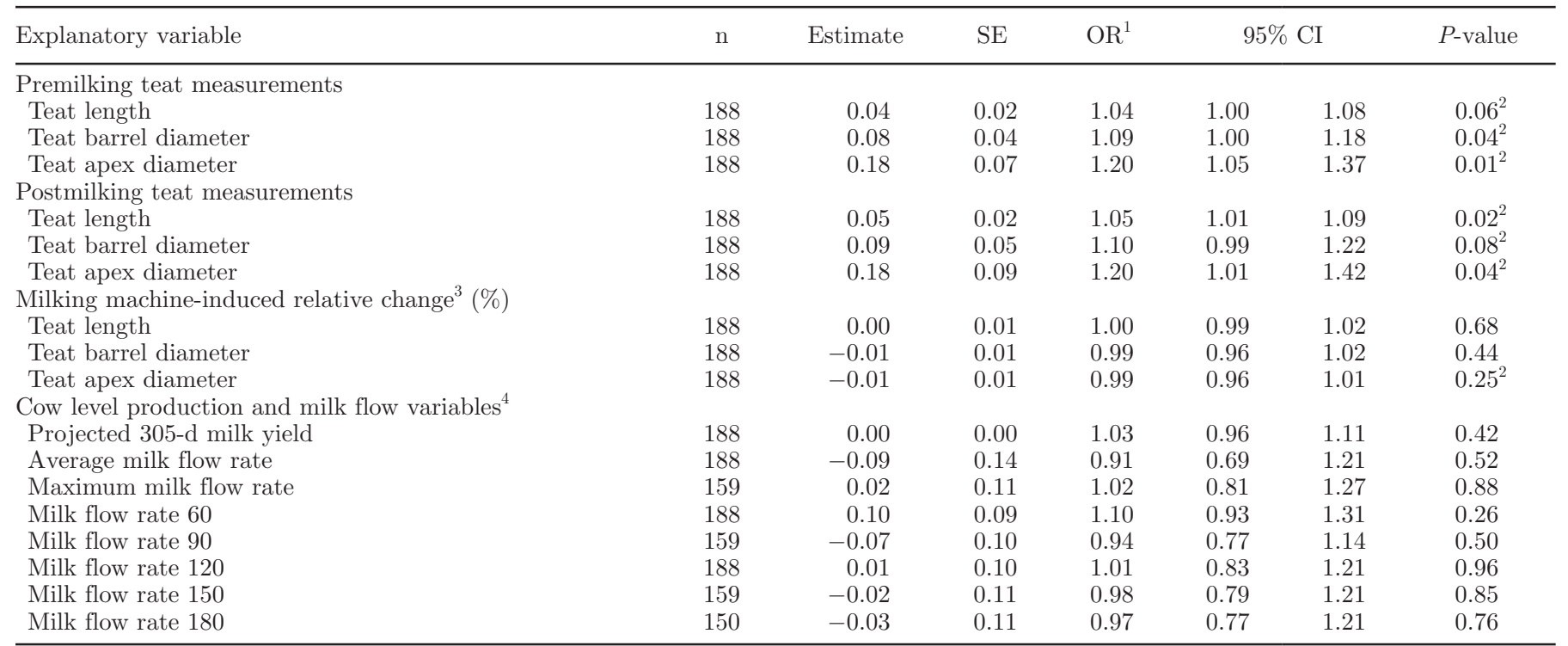

${ }^{1}$ Odds ratio (OR) for a quarter developing clinical mastitis as compared with remaining healthy. Odds ratio for pre- and postmilking teat measurements are for each 1-mm increase in each teat dimension. Odds ratio for milking machine-induced relative change each are for each $1 \%$ increase in relative change. Odds ratio for projected 305-d milk yield are for each 500-kg increase in the projected milk yield. Odds ratio for milk flow rates are for each $1 \mathrm{~kg} / \mathrm{min}$ increase in the milk flow rate in their respective milking interval.

${ }^{2}$ Eligible for inclusion in multivariable model for case-control study.

${ }^{3}$ (Postmilking value - premilking value)/premilking value $\times 100$.

${ }^{4}$ Cow level production and milk flow variables for those cows who have milk flow data available: Projected 305-d milk yield $=$ adjusted 305-d milk production $(\mathrm{kg})$; average milk flow rate = average milk flow from initiation of milk flow to cluster removal (kg/min); maximum milk flow rate $=$ defined as the peak flow rate $(\mathrm{kg} / \mathrm{min})$; milk flow rate $60=$ milk flow at $30-60 \mathrm{~s}(\mathrm{~kg} / \mathrm{min})$ after unit attachment; milk flow rate $90=$ milk flow at $60-90 \mathrm{~s}(\mathrm{~kg} / \mathrm{min})$ after unit attachment; milk flow rate $120=$ milk flow at $90-120 \mathrm{~s}(\mathrm{~kg} / \mathrm{min})$ after unit attachment; milk flow rate $150=$ milk flow at $120-150 \mathrm{~s}(\mathrm{~kg} / \mathrm{min})$ after unit attachment; milk flow rate $180=$ milk flow at $150-180 \mathrm{~s}(\mathrm{~kg} / \mathrm{min}) \mathrm{after}$ unit attachment. 
the average of their herd mates were found to have increased risk of developing clinical mastitis (Slettbakk et al., 1995).

Milking machine-induced changes in teats were not associated with the occurrence of clinical mastitis during this experiment. Milking machine-induced teat changes (e.g., teat congestion) were not associated with clinical mastitis. Teat congestion, as defined by Hamann and Mein (1990), is the intravascular accumulation of fluids and is not expected to cause long-term deleterious effects on teats, although it is a precondition for the development of edema, a condition that may cause longer term effects on teat health (Mein, 2012). Teat congestion and edema may compromise teat canal defense mechanisms and increase risk of intra-mammary infection (Mein, 2012). Zwertvaegher et al. (2013) found a significant association of the relative change of the teat barrel diameter with increased quarter SCC. The authors attributed the increased SCC to larger teat orifices and wider teat canals on bigger teats. Possible differences between Zwertvaegher et al. (2013) and the current study may be attributable to different outcomes that were evaluated, use of different methodologies to measure the teats, different number of animals measured, different exposure to pathogens, and differences in the liners used in the European study (mostly medium-bore liners) and the ones used in this study (narrow-bore liners only).

Milk flow variables analyzed in this study were not related to increased incidence of clinical mastitis. Neijenhuis (2011) described a positive association between peak flow rate and susceptibility to IMI, possibly due to a larger teat canal diameter in these quarters. Hammer et al. (2012) found that quarters with faster peak milk flow rates were at increased risk of clinical mastitis. In recent years, dairy cattle have been selected for increased milking speed and parlor throughput (Ruegg and Erskine, 2014). It is possible that selecting for milking speed has had an influence on teat anatomic characteristic (e.g., potentially wider teat apex) and has led to a possible reduction in the efficacy of teat canal defense mechanisms (Moore et al., 1983; Reinemann et al., 2008; Neijenhuis, 2011).

These results indicate the need for further research about teat dimensions and their influence on mastitis risk in a larger set of farms, larger group of cows, different type of liners, and additional risk factors such as type of bedding and hyperkeratosis scores. Milking machine effects on teats are not well defined and additional research is required to better understand this relationship. Premilking teat apex diameter is positively associated with incidence of clinical mastitis.
In contrast, milking machine-related changes in teat dimensions and occurrence of clinical mastitis were not associated in the current study.

\section{ACKNOWLEDGMENTS}

The authors thank the personnel of the University of Wisconsin Emmons Blaine Dairy Cattle Research Center for their help. The project was partially funded by the government of Colombia and the Departamento Administrativo de Ciencia, Tecnología e InnovaciónCOLCIENCIAS, Bogota, Colombia, and by unrestricted gift funds of the senior author (PLR), University of Wisconsin, Madison.

\section{REFERENCES}

Erskine, R. J., S. Wagner, and F. J. DeGraves. 2003. Mastitis therapy and pharmacology. Vet. Clin. North Am. Food Anim. Pract. 19:109-138.

GEA Farm Technologies. 2010. ClassicPro Silicone Liners. Accessed Jan. 10, 2015. http://www.gea-farmtechnologies.com/Images/ PN7755-1000-083_USC_ClassicPro\%20GQ_0912_tcm90-111006. pdf.

Hamann, J., and G. A. Mein. 1990. Measurement of machine-induced changes in thickness of the bovine teat. J. Dairy Res. 57:495-505.

Hammer, J. F., J. M. Morton, and K. L. Kerrisk. 2012. Quarter-milking-, quarter-, udder- and lactation-level risk factors and indicators for clinical mastitis during lactation in pasture-fed dairy cows managed in an automatic milking system. Aust. Vet. J. 90:167-174.

Hogan, J. S., R. Gonzalez, R. Harmon, S. Nickerson, S. Oliver, J. Pankey, and K. Smith. 1999. Laboratory Handbook on Bovine Mastitis. National Mastitis Council, Madison, WI.

Mein, G. A. 2012. The role of the milking machine in mastitis control. Vet. Clin. North Am. Food Anim. Pract. 28:307-320.

Moore, R. K., J. E. Moxley, B. W. Kennedy, and E. B. Burnside. 1983. Relationships between speed of milking and somatic cell count and production in Holsteins. Can. J. Anim. Sci. 63:781-789.

Neijenhuis, F. 2011. Mastitis therapy and control | Role of milking machines in control of mastitis. Pages 440-446 in Encyclopedia of Dairy Sciences. 2nd ed. J. W. Fuquay, ed. Academic Press, San Diego, CA.

Reinemann, D., R. Bade, M. Zucali, C. Spanu, and P. Ruegg. 2008. Understanding the influence of machine milking on teat defense mechanisms. Pages 323-331 in Proc. Int. Conf. on Mastitis Control, The Hague, the Netherlands.

Ruegg, P. L., and R. J. Erskine. 2014. Mammary Gland Health. Pages 1015-1043 in Large Animal Internal Medicine. 5th ed. Mosby Elsevier, St. Louis, MO.

Seykora, A. J., and B. T. McDaniel. 1985. Udder and teat morphology related to mastitis resistance: A review. J. Dairy Sci. 68:2087-2093.

Slettbakk, T., A. Jørstad, T. B. Farver, and J. C. Holmes. 1995. Impact of milking characteristics and morphology of udder and teats on clinical mastitis in first-and second-lactation Norwegian cattle. Prev. Vet. Med. 24:235-244.

Zucali, M., D. J. Reinemann, R. Bade, and A. Tamburini. 2008. Effects of liner compression on teat-end Hyperkeratosis. Accessed Jan. 10, 2015. http://milkquality.wisc.edu/wp-content/uploads/2011/10/ compression-on-teat-end-hyerkeratosis.pdf.

Zwertvaegher, I., S. De Vliegher, B. Verbist, A. Van Nuffel, J. Baert, and S. Van Weyenberg. 2013. Short communication: Associations between teat dimensions and milking-induced changes in teat dimensions and quarter milk somatic cell counts in dairy cows. J. Dairy Sci. 96:1075-1080. 